\title{
Synthesis of the Fe-6.5\% wt. Si alloy by mechanical alloying
}

\author{
Cristina-Daniela STANCIU ${ }^{1,2, a}$, Florin POPA ${ }^{1, b}$, lonel CHICINAŞ ${ }^{1, c^{*}}$, \\ Olivier ISNARD ${ }^{2, d}$ \\ ${ }^{1}$ Materials Science and Engineering Department, Technical University of Cluj-Napoca \\ ${ }^{2}$ Néel Institute, CNRS / University J. Fourier, Grenoble, France \\ acristina.stanciu@stm.utcluj.ro, ${ }^{b}$ florin.popa@stm.utcluj.ro, ${ }^{c}$ ionel.chicinas@stm.utcluj.ro, \\ dolivier.isnard@neel.cnrs.fr
}

\begin{abstract}
Keywords: Fe-Si alloy, mechanical alloying, soft magnetic material, nanocrystalline
\end{abstract}
\begin{abstract}
Fe-Si alloy with a large Si content of $6.5 \mathrm{wt} . \%$ is obtained in nanocrystalline state by mechanical alloying of elemental iron and silicon powders. The mechanical alloying process was carried out using a high energy ball mill in argon atmosphere. Samples were collected after $0.5,1,2$, 4, 6 and 8 hours of ball milling. The X-ray diffraction (XRD) studies indicate that after 4 hours of milling the Fe-Si alloy is formed. The powder magnetisation decreases upon increasing the milling time up to 4 hours as a consequence of the Fe-Si alloy formation. Upon heating, the DSC studies show the $\mathrm{Fe}_{3} \mathrm{Si}$ compound formation in the samples milled for milling times lower than 6 hours. Also, the Curie temperature of the alloy was evidenced.
\end{abstract}

\section{Introduction}

Fe-Si alloys are used in many applications as magnetic cores due to their combination of low coercivity, high magnetic permeability and low eddy current losses [1-3]. By adding silicon, the alloy magnetic anisotropy and coercivity decreases, while the electrical resistivity increases resulting in the decrease of eddy current losses, making these alloys suitable for AC applications [4]. Moreover, silicon addition increases the fragility of the material, limiting in practice the amount of $\mathrm{Si}$ at $4.5 \mathrm{wt} \%$ for sheet obtained by rolling [5].

Fe-Si alloys, with high Si content and with nanocrystalline grain size, can be produced by various methods: magnetron sputtering, rapid quenching, physical vapour deposition, co-injection, mechanical alloying etc. [6-8].

Mechanical alloying is a method for producing materials that are difficult or even impossible to alloy by means of other procedures. It is one of the most used techniques for fabricating nanocrystalline materials $[9,10]$.

In addition to our previous study on the synthesis of the $\mathrm{Fe}-10 \% \mathrm{Si}$ nanocrystalline powders [11], in this study we report on obtaining the nanocrystalline $\mathrm{Fe}-6.5 \% \mathrm{Si}$ alloy powder by highenergy ball milling process, starting from elemental Fe and Si powders. The structural, thermal and magnetic properties of this Fe-Si alloys were also investigated.

\section{Experimental}

A nanocrystalline Fe-Si alloy containing 6.5\% wt. Si was obtained by mechanical alloying. Elemental iron (NC 100.24, Höganäs) and silicon (Alfa Aesar) powders were milled together in a Fritch Pulverisette 4 planetary ball mill, under argon atmosphere [11]. The starting mixture, Fe and $\mathrm{Si}$, was homogenized in a Turbula-type apparatus for 15 minutes, thus obtaining the starting sample (ss).

Ball to powder weight ratio was $10: 1$ and the milling time has been varied up to 8 hours. Samples were collected after $0.5,1,2,4,6$ and 8 hours of ball milling. In order to remove internal 
stresses induced during milling and to finish the solid state reaction, the as-milled samples were subjected to annealing at $400{ }^{\circ} \mathrm{C}$ for 4 hours in an Ar atmosphere.

The evolution of the alloy formation process was investigated by X-ray diffraction (Siemens D5000R). The XRD patterns were recorded in the 20 to $120^{\circ}(2 \theta)$ angular range, using Co K alpha radiation $(\lambda=1.79026 \AA)$.

The differential scanning calorimetry (DSC) curves were recorded on Netzsch DTA404S apparatus using a heating rate of $10^{\circ} \mathrm{C} / \mathrm{min}$ in argon atmosphere.

The magnetization curves $-\mathrm{M}(\mathrm{H})$ - were recorded at $300 \mathrm{~K}$, using the extraction sample method in a continuous magnetic field of up to $10 \mathrm{~T}$. The saturation magnetisation values were derived from the magnetization curves obtained in magnetic field higher than $4 \mathrm{~T}$, after reaching the magnetic saturation of the sample magnetization.

\section{Results and discussions}

Figure 1 shows the $\mathrm{X}$-ray diffraction patterns for the powder milled for $0.5,1,2,4,6$ and 8 hours and for the starting mixture (ss). It can be observed that the silicon peaks disappear from the diffraction patterns after 4 hours of milling, consequently indicating the alloy formation.

After $4 \mathrm{~h}$ of milling, the diffraction peaks are broadened due to the decrease of the crystallite size and the second order internal stress induced by the milling process. The mean crystallite size diminishes with increasing the milling time, toward nanocrystalline range.

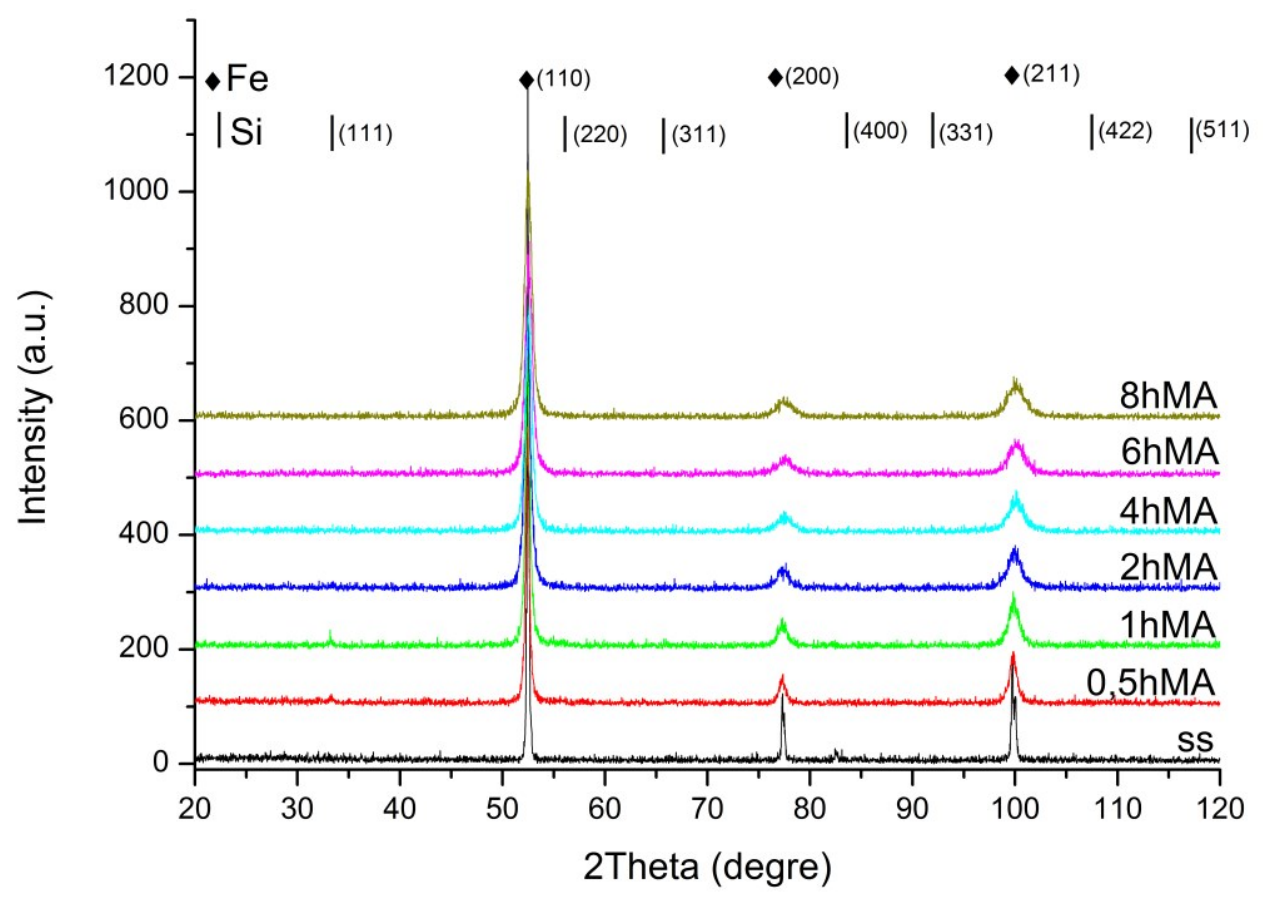

Fig. 1. X-ray diffraction patterns for the powder milled for 0.5, 1, 2, 4, 6 and 8 hours. SS denotes the starting sample.

The heating DSC curves (figure 2) show an exothermic peak at about $450^{\circ} \mathrm{C}$, which is due to the forming of the $\mathrm{Fe}_{3} \mathrm{Si}$ alloy during heating, as has been reported for the $\mathrm{Fe}-10 \% \mathrm{Si}$ mechanically alloyed powders [11]. The corresponding DSC peak intensity decreases with increasing the milling time, upon alloy formation by milling. 


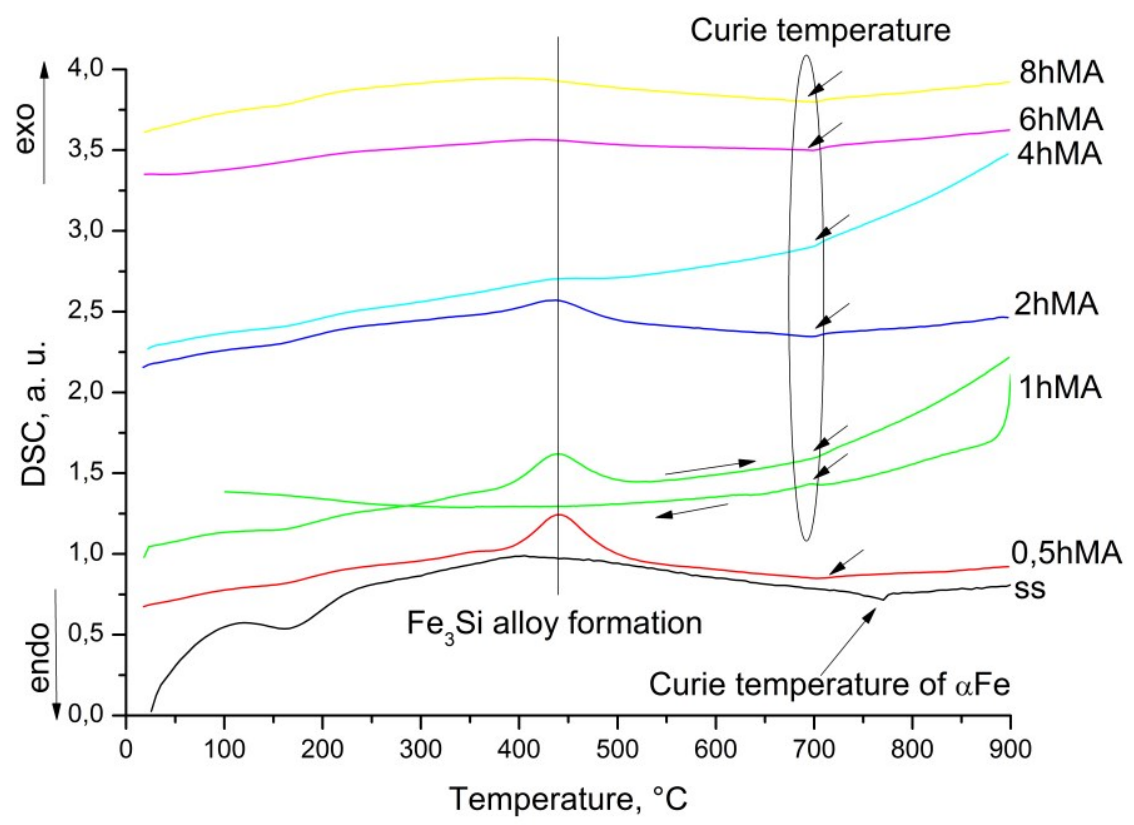

Fig. 2. Heating DSC curves for the Fe-6.5\%wt. Si powders milled for 0.5, 1, 2, 4, 6 and 8 hours respectively. For the $1 \mathrm{~h}$ milled sample both heating and cooling DSC curves are plotted; ss denotes the starting sample.

The Curie temperature of the alloy is evidenced on the DSC curves as a change in slope curve, marked with arrows in the figure 2. It can also be noted that the Curie temperature decreases from $770^{\circ} \mathrm{C}$ for the starting sample (Curie temperature corresponding for pure iron) to $700^{\circ} \mathrm{C}$ for the sample milled for 8 hours. This is also confirmed by thermomagnetic measurements (the results will be published elsewhere).

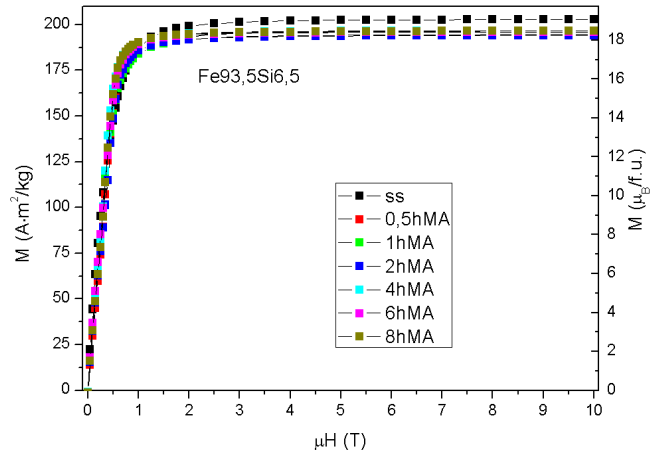

a)

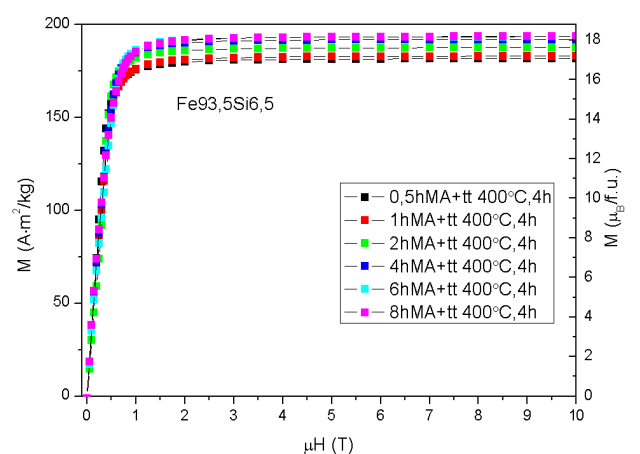

b)

Fig. 3. Room temperature magnetization versus magnetic field for the as-milled powder (a) and for the milled and subsequently annealed powder at $400^{\circ} \mathrm{C}$ for $4 \mathrm{~h}$ (b).

Figure 3 presents the magnetization curves of the mechanically alloyed Fe-Si powder (a) and the mechanically alloyed and annealed powder (b). It can be observed that the magnetization decreases with increasing milling time for the mechanically alloyed sample, while for the mechanically alloyed and subsequently annealed samples, the magnetization increases with increasing milling time. 


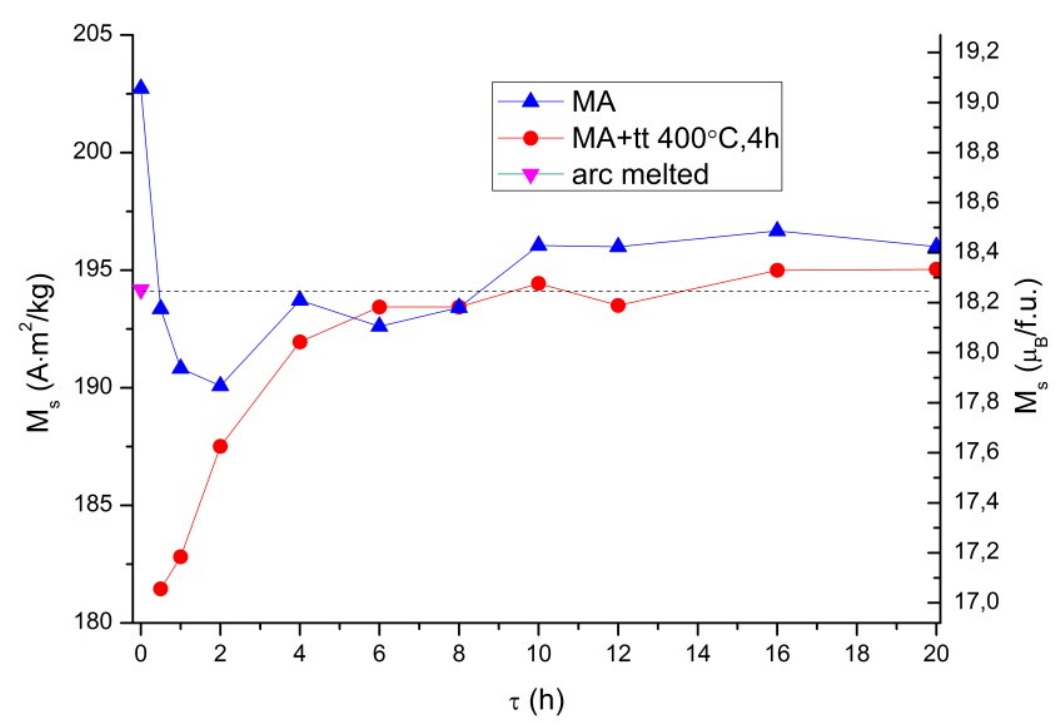

Fig. 4. Evolution of the powder saturation magnetization versus milling time, recorded at $300 \mathrm{~K}$ for the as-milled samples, milled and annealed samples and the arc melted sample.

Figure 4 shows the saturation magnetization as a function of milling time for the mechanically alloyed samples, mechanically alloyed and subsequently annealed samples comparison to that of the arc melted sample (used as reference for the magnetic properties of the bulk alloy). The saturation magnetization for the mechanically alloyed samples decreases rapidly until 2 hours of milling; this is due to the progressive alloy formation. After 4 hours of milling, the Fe-Si alloy saturation magnetization present a slight increase, which suggests a possible iron contamination of the powder from the milling equipment [12]. After 8 hours of milling, the saturation magnetization has the same value for the milled samples and the milled and subsequently annealed at $400^{\circ} \mathrm{C}$ for 4 hours. But for lower milling times, the saturation magnetization of the milled and subsequently annealed samples is lower than for the as-milled samples. This can be due to the formation of $\mathrm{Fe}_{3} \mathrm{Si}$ phase during annealing, a phase with a lower magnetization compared to Fe and Fe-6.5\% $\mathrm{Si}$ [13].

\section{Summary}

The Fe-Si alloy with a Si content of 6.5 wt. \% was successfully synthesized from elemental iron and silicon powders by mechanical alloying. Changes in the saturation magnetization as a function of milling time show a continuous formation of the alloy up to $4 \mathrm{~h}$ of milling, followed by an almost stationary stage. By taking into account the X-ray diffraction it can be concluded that the alloy is formed after 8 hours of milling and the nanocrystalline state is achieved. Annealing at $400{ }^{\circ} \mathrm{C}$ for 4 hours helps improving the alloy formation at short milling times. The saturation magnetization remains the same after 8 hours of milling for both as-milled and milled and subsequently annealed samples.

\section{Acknowledgement}

This work was supported by CNCSIS-UEFISCSU, project number PN-II-ID-PCE-2012-4-0632 and the French-Romanian cooperation Programme Hubert Curien (PHC) - Brancusi, and project number 711/2012 (in Romania) and 28847YK (in France).

C. D. Stanciu is grateful for the grant POSDRU/159/1.5/S/137070 (2014) of the Ministry of National Education, Romania, co-financed by the European Social Fund - Investing in People, within the Sectorial Operational Programme Human Resources Development 2007-2013. 


\section{References}

[1] J. Ding, Y. Li, L.F. Chen, C.R. Deng, Y. Shi, Y.S. Chow, T.B. Gang, Microstructure and soft magnetic properties of nanocrystalline Fe-Si powders, J. Alloys Compd. 314 (2001) 262-267.

[2] D. Ruiz, T. Ros-Yáñez, L. Vandenbossche, L. Dupré, R.E. Vandenberghe, Y. Houbaert, Influence of atomic order on magnetic properties of Fe-Si alloys, J. Magn. Magn.Mater. 290-291 (2005) 1423-1426.

[3] S. Kim, Y. J. Lee, B. Lee, K.H. Lee, K. Narasimhan, Y.D. Kim, Characteristics of nanostructured Fe-33 at.\%Si alloy powders produced by high-energy ball milling, J. Alloys Compd. 424 (2006) 204-208.

[4] M. Abdellaoui, C. Djega-Mariadassou, E. Gaffet, Structural study of Fe-Si nanostructured materials, J. Alloys Compd. 259 (1997) 241-248.

[5] J. Barros, T. Ros-Yanez, L. Vandenbossche, L. Dupre', J. Melkebeekb, Y. Houbaert, Journal of Magnetism and Magnetic Materials, 290-291 (2005) p. 1457-1460

[6] Guangke Tian, Xiaofang Bi, Fabrication and magnetic properties of $\mathrm{Fe}-6.5 \% \mathrm{Si}$ alloys by magnetron sputtering method, Journal of Alloys and Compounds 502 (2010) 1-4

[7] R.D. Cava, D.P. Oliveira, T.Yonamine, J.J.A. Moreira, W.J. Botta, C.S. Kiminami, C. Bolfarini, Microstructural characterization of high-silicon iron alloys produced by spray forming and coinjection of Si particles, Journal of Alloys and Compounds, 509S, (2011) p. S254-S259.

[8] Y.F. Liang, Microstructure and mechanical properties of rapidly quenched Fe-6.5 wt.\% Si alloy, Journal of Alloys and Compounds, 504S (2010) p. S476-S479

[9] C. Suryanarayana, Mechanical alloying and milling, Progress in Materials Science, 46 (2001) p. 1-184 [10] I. Chicinaş, Soft Magnetic Nanocrystalline Powders Produced by Mechanical Alloying Routes, J. Optoelectron, Adv. Mater. 8 (2006) 439-448

[11] C. D. Stanciu, T.F. Marinca, F. Popa, I. Chicinaş, O. Isnard, Synthesis of the Fe-10\%Si nanocrystalline powder by mechanical alloying, Solid State Phenomena, Vol. 216 (2014) pp 283287.

[12] T.F. Marinca, I. Chicinaş, O. Isnard, V. Popescu, Nanocrystalline/nanosized $\mathrm{Ni}_{1-\gamma} \mathrm{Fe}_{2+\gamma} \mathrm{O}_{4}$ ferrite obtained by contamination with $\mathrm{Fe}$ during milling of $\mathrm{NiO}-\mathrm{Fe}_{2} \mathrm{O}_{3}$ mixture. Structural and magnetic characterization, J. Am. Ceram. Soc. 96 (2013) 469-475

[13] P. K. Muduli, K.-J. Friedland, J. Herfort, H.-P. Schönherr, K. H. Ploog, Composition dependent properties of Fe3Si films grown on GaAs(113)A substrates, Journal of Applied Physics 105, 07B104 (2009). 